\title{
Research Square \\ Prediction of Iranian EFL Teachers' Burnout Level Using Machine Learning Algorithms and Maslach Burnout Inventory
}

Shima Baniadam Dizaj ( $\sim$ baniadam.shima@gmail.com )

Kharazmi University https://orcid.org/0000-0003-1678-5108

Shahla Baniadam Dizaj

Kharazmi University - Karaj

Original article

Keywords: Classification algorithms, Burnout, Machine learning, Maslach Burnout Inventory

Posted Date: September 29th, 2021

DOI: https://doi.org/10.21203/rs.3.rs-810170/v2

License: (c) (i) This work is licensed under a Creative Commons Attribution 4.0 International License.

Read Full License 


\title{
Prediction of Iranian EFL Teachers' Burnout Level Using Machine Learning Algorithms and Maslach Burnout Inventory
}

\author{
Shima Baniadam Dizaj ${ }^{10000-0003-1678-5108]}$, Shahla Baniadam Dizaj ${ }^{1}$ \\ ${ }^{1}$ Kharazmi University, Tehran, Iran \\ baniadam.shima@gmail.com
}

\begin{abstract}
Burnout is that the end result of excessive work-associated pressure and it is categorized through emotional, psychological, and bodily exhaustion. we can remember it as a cutting-edge epidemic withinside the coaching career likewise as distinct professions. The measures that could have an impact on a lecturer and may reason burnout are categorized as Depersonalization, Emotional Exhaustion, Personal Accomplishment. alevin though articles on educator burnout range of their approach, they incline to specialize withinside the reasons of burnout, the manner to evaluate the symptoms and symptoms of burnout, strategies to forestall burnout, and/or subsequent steps for administrators and teachers. The principal problem that has been incomprehensible is the prediction of acquiring burned out. Through prediction, we can reduce lower back the fees of the burnout effect on teachers, students, schools, and society and forestall its results like depression, coronary failure, or possibly suicide. Our goal is to investigate and are expecting the burnout stage in English as a faraway Language (EFL) instructor. we're going to use Maslach Burnout Inventory (MBI) to collect a dataset and stay the three subscales of instructor burnout: emotional exhaustion, depersonalization, and decreased non-public accomplishment. whilst studying the amassed dataset that consisted of 1433 teachers' data, nine system getting to know type algorithms through enforcing exploitation python programing language is implemented and accuracy is hired as an overall performance parameter.
\end{abstract}

Keywords: Classification algorithms, Burnout, Machine learning, Maslach Burnout Inventory

\section{Introduction}

Pollard and Collins (Pollard \& Collins, 2005) state "teaching is a complex and highly skilled activity which, higher than all, needs room lecturers to exercise judgment to decide the way to act". Every person in a role as a teacher has his/her particular methods and ways and thoughts of effective teaching. This involves the belief that "effective student learning is the end outcome of educational practices" (Donald, 2000).

Effective and successful teaching is not a no-brainer and teachers need to practice hard enough to achieve effective teaching. Considering the fact that effective teaching requires a high level of attention and training, it can be considered as one of the most demanding and challenging professions among other professions (Kyriacou, 2001). Teachers are expected to perform a wide range of tasks and often feel that their tasks are constantly changing (Kyriacou, 2001; Bryne, 1998). In the past, teachers used an authoritarian style of discipline to guide and teach students, and students went to class to learn the knowledge (Okojie, 2011). However, in modern pedagogy, the emphasis is on addressing the needs of learners and adapting the style of teaching to meet those needs (Okojie, 2011). As the task of teachers becomes more and more difficult in the face of the general changes in educational systems, some teachers are leaving the profession. Therefore, many researchers working in the field of teacher education have paid attention to teacher burnout, and it has become one of the most important issues in the field.

Burnout, defined as "a series of unsuccessful attempts by an individual to cope with various perceived distress states" (Gold and Roth, 1993), was originally invented by Herbert Freudenberger in the 1970s and received much more 
empirical attention thanks to Christine. Maslach (Gold and Roth, 1993). Most researchers define "burnout" as an extreme reaction to some form of occupational stress (e.g. (Dedrick \& Raschke, 1990; Wiśniewski \& Gargiulo, 1997)), while others believe that "work stress" and "burnout" are the same (Male \& and May 1997). According to Farber (Farber, 1991), stress and burnout are distinct phenomena, but difficult to distinguish without empirical evidence. Therefore, it can be concluded that there is a relationship between occupational stress and burnout. Additionally, some stressors can increase teachers' workloads and lead to burnout. To call some of those stressors, you can assume the loss of support (from control and/or colleagues), workload, disruptive students, function ambiguity, function conflict, loss of resources, and stressors. environmental situations along with noise, air first-rate, and temperature (Abel and Sewell, 1999; Bivona, 2002; Hansen and Sullivan, 2003). Many of us are unaware that burnout is a form of work depression. According to an evaluation posted withinside the Journal of Psychotherapeutics (Schonfeld \& Bianchi, 2016; Bianchi, Schonfeld., \& Laurent, 2014), there may be a massive overlap among burnout and depression. Burnout reasons many educators to have extra depression, which includes a lack of hobby or pride in activities, temper swings, and weariness. Overall, the more mood disorder they have, the much more burnout signs they have. Another study published by Stress Management (Leiter \& Robichaud, 1997) in International Journal showed that ninety percent of participants who scored high on burnout met the standards for conditional classification as depression. Given the magnitude of this correlation, it is important to note the fact that burnout is an entirely different form of depression.

According to the Yankee Federation of Teachers' 2017 pedagogue Quality of labor Life Survey, sixty-one percent of lecturers said their work was forever or typically stressful. Even as alarming, if no more so, fifty-eight percent of respondents cited poor psychological state as a result of that stress. Since burnout is way more serious than is mostly portrayed, it is necessary to work out however we are able to predict the burnout in teachers and this is often our inspiration for this paper. Because of the overlap between burnout and depression, faculty who are affected by burnout may seek medical and/or psychological help to manage their (depressive) burnout symptoms. It is critical that faculty proactively address psychological issues in the workplace, as in some cases this leads to unplanned consequences (e.g., ineffective teaching, faculty self-harm and/or suicide, etc.). To address this far too common problem, teachers in administration should take very different approaches to preventing and treating burnout. Some strategies are presented below.

\section{Literature review}

\subsection{Teacher burnout}

Teacher burnout is described due to extended pressure, that is itself observed via way of means of physiological and biochemical modifications in trainer which in flip results in emotional and bodily exhaustion, complaints, and continual bodily and intellectual conditions (Abel \& Sewell, 1999) According to Maslach, Jackson, and Leiter (Leiter \& Robichaud,1997), trainer burnout encompasses 3 major additives which include emotional exhaustion, decreased private accomplishment, and depersonalization. Emotional exhaustion is being emotionally overtired, depersonalization manner manifesting bad reactions to humans, and sooner or later decreased private accomplishments talk over with a bad assessment of oneself. Maslach and Leiter (Maslach \&Leiter, 1999) proposed a version of trainer burnout with 5 major elements of organizational characteristics, private traits of instructors, project traits, social support, political, policy, and financial context, and ecology of the school. The version shows that trainer burnout includes, and is the end result of, exhaustion, depersonalization, and decreased accomplishment. It appears that as withinside the system version of burnout, emotional exhaustion takes place first and results in the upward thrust of depersonalization, while decreased private accomplishment develops separately. This version observes the approaches trainer burnout affects college students' conduct and outcomes. High tiers of trainer burnout might also additionally bring about much less wonderful remarks or greater grievance of college students, which might also additionally, in flip, bring about much less involvement of college students withinside the classroom. 
Regarding empirical research in burnout, Schaufeli, Bakker, and Van Rhenen (Schaufeli, Bakker, \& Van Rhenen, 2009) investigated the affiliation amongst process demands, assets, burnout, paintings engagement, and illness absenteeism. The consequences confirmed that loss of assets and excessive process call for can expect burnout and burnout is undoubtedly associated with illness absenteeism. Furthermore, it turned into found that there may be a round dating among those variables. For instance, preliminary paintings engagement predicts assets which once more complements paintings engagement and decreases burnout. The findings of another (Aloe, Shisler, Norris, Nickerson \& Rinker, 2014) discovered that college students' misbehavior correlates each undoubtedly and notably with 3 dimensions of trainer burnout (emotional exhaustion, depersonalization, and decreased private accomplishment). Moreover, it turned into determined that emotional exhaustion is the issue maximum correlated with college students' misbehavior, then depersonalization, and sooner or later decreased private accomplishment.

Various frameworks practice straightforwardly to know-how pressure and the function that coping performs in dealing with pressure. These frameworks can deliver a premise to know-how how strategies for coping effect the extent of pressure person stories while faced with a ability stressor (Gelman, 2008). Research has tested that occupational pressure in instructors may be greater big than occupational pressure in special occupations (Travers \& Cooper, 1996). A look at via way of means of Cooper and Marshall (Cooper \& Marshall, 1977), determined that teachers who placed their occupational pressure as 'excessive' encountered a greater noteworthy fee of coronary heart attack, stroke, and said greater intellectual ailments than humans in special occupations who likewise prominent their pressure stage as 'excessive'. Adams (Adams, 1999) determined that the results of trainer pressure can provide implications for his or her capacity to teach, their very own lives, and their cooperation with their college students.

Other studies have said teacher strain as an incredible contributing element to trainer burnout, making teachers lower delight with education and leave the profession (Parkay, Greenwood, Olenjik \& Proller, 1988; Borg \& Riding, 1991). Work-very own circle of relative's conflicts was one of the primary predictors of emotional exhaustion - the middle length of burnout (Rajendran, Watt \& Richardson, 2020). According to Corbin et al., (2019), close to teacher-student relationships stated higher tiers of personal accomplishment, whilst more conflictual relationships were associated with multiplied emotional exhaustion.

\subsection{Machine learning usage in prediction burnout and stress}

Machine learning might be a huge subject of facts and there is no unmarried definition. In general, the time period is thought in its broader and narrower sense. The large know-how of device mastering refers back to the examiner of algorithms and structures that enhance their information and consequences except gaining expertise (Flach, 2012). It is essential to do not forget that device mastering and information mining equipment are derived from the strategies of synthetic intelligence and multidimensional statistics (Tan, Steinbach \& Kumar, 2016). These days and via way of means of enhancing the consequences of various device mastering algorithms prediction have become one of the maximum usages of device mastering algorithms. Prediction includes the use of a few variables to expect unknown values of different information and supervised strategies are particularly used for this purpose (Mitchell, 2017).

Although device mastering has been advancing for numerous years, it has simplest lately been used for behavioral sciences (DelPozo-Banos \& Petkov, et.al, 2018). For instance, those algorithms are utilized in computational psychiatry to enhance the analysis of temper disorders: strain (Silva \& Aguiar, et al., 2020), depression (Webb \& Cohen, et al, 2020), and suicidality (Kessler \& Warner, et al, 2015). There are one-of-a-kind approaches to gather information for the use of device mastering, for instance, Kaczor and colleagues (2020) used device mastering strategies to come across worrying conditions the use of virtual sensors worn via way of means of emergency medication physicians and a selfevaluation questionnaire.

Lu et al. (2020) proposed a device framework for real-time strain tracking and intervention. Different from different present strain detecting device frameworks, we combine strain tracking and corresponding strain intervention strategies right into a device. This device can assist human beings with high-strain risks, which include policemen and pilots, to reveal and intrude of their strain in time. Gedam and Paul (2020) first extracted the functions the use of diverse algorithms and that they implemented device mastering algorithms to construct a type version. It is located that functions 
extracted the use of Heart fee, Heart fee variability, and pores and skin conductance are greater beneficial withinside the prediction of strain stage of a person at the same time as Support vector device, Random Forest, and K-Nearest Neighbor are the simplest type algorithms. Ahuja and Banga (2019) gathered a dataset to come across intellectual strain in college students the use of device mastering. Their dataset includes 206 student's information. They used 4 type algorithms and implemented sensitivity, specificity, and accuracy as overall performance parameters.

Prediction burnout in one-of-a-kind elements and jobs has very blessings for personnel and employers. Also, via way of means of prediction, we will lessen the prices of remedy and save you the awful consequences of burnout on personnel' consequences. All personnel primarily based totally at the one-of-a-kind conditions are liable to burnout. Civil servants, assisting experts which include caregivers, teachers, and social employees in toddler welfare practice. Working beneath Neath workload pressures can result in troubles like burnout (Grządzielewska, 2021). An instance is a piece of Bauernhofer et al. (2018), whose studies pattern blanketed 103 sufferers clinically identified with occupational burnout. Three burnout subtypes have been identified: the burned-out subtype, the exhausted/cynical subtype, and the exhausted subtype. Main consequences confirmed that the burned-out subtype turned into quite a few depressed than the others, however, no difference turned into recognized among burned-out and exhausted/cynical subtypes with strain and sociodemographic characteristics.

Lee et al. (2020) used k-approach to the institution of approximately 1000 nurses running in a clinical middle in Taiwan into classes. Next, the convolutional neural network (CNN) deep mastering approach turned into implemented to the predictive version to estimate 38 parameters for the burnout pattern. Kurbatov et al. (2020) implemented kapproach unsupervised clustering ( $\mathrm{k}$-approach analysis) and supervised clustering (k-approach cluster institution) to discover and expect burnout in surgical trainees. As gathered information indicates the strain, and fitness of the respondents have been predicted. The empirical consequences confirmed that the use of those strategies to account for person variations led to huge overall performance improvements (Taylor \& Jaques, et al, 2017). Zhernova et al. (2020) used Maslach Burnout Inventory (Maslach, Jackson \& Leiter, 1997) to expect early stipulations of burnout. Applying device mastering processes allowed to successfully expect burnout in $70 \%$ of cases.

\section{Methodology}

\subsection{Dataset and preprocessing}

Our proposed technique is the usage of device getting to know type algorithms on classifying EFL instructors' burnout levels. The player instructors taking the survey tool protected 1433 Iranian instructors (1042 ladies and 391 males) coaching English at personal language institutes.

The Maslach Burnout Inventory (Maslach, Jackson \& Leiter, 1997) became used to degree the 3 subscales of trainer burnout: emotional exhaustion (nine items, e.g. I experience used up on the give up of the workday), depersonalization (five items, e.g. I experience I deal with a few college students as though they have been impersonal objects), and decreased non-public accomplishment (eight items, e.g. I even have carried out many profitable matters on this job). Participants finished the size on a seven-factor Likert kind scale starting from 0 (never) to 6 (always). In the questionnaire questions $\# 1, \# 2, \# 3, \# 6, \# 8, \# 13, \# 14, \# 16, \# 20$ are associated with emotional exhaustion, \#5, \#10, \#11, $\# 15, \# 22$ are associated with depersonalization and $\# 4, \# 7, \# 9, \# 12, \# 17, \# 18, \# 19, \# 21$ are for non-public accomplishment.

To acquire this dataset, we will be inclined to apply a legitimate and dependable shape (Maslach, Jackson \& Leiter, 1997) as Maslach Burnout Inventory-Human Services Survey for Medical Personnel (MBI). One contributor to the ascertained inconsistencies in shaping divided burnout consequences at the MBI would possibly also be the lack of readability regarding the approach of subscale rankings. historical interest techniques do not permit customers to completely evaluate subscale rankings with the content material of factors to interpret their meaning. we will be inclined to aimed to shape reaction profiles describing the danger of burnout signs throughout standardized MBI subscale 
rankings in Iran's EFL instructors. we have a tendency to made a course mapping raw (total) MBI subscale ranking to scaled rankings and related reaction profiles.

Then, Statistical Package for Social Sciences (SPSS 18) became run to discover the burnout stage of every trainer. As its miles indicated in Table1, the academics have been divided into three groups: high-burned-out (HB), mid-burnedout (MB), and low-burned-out (LB). To enhance the overall performance of our version we carried out K-fold crossvalidation to boom the quantity of records in our accrued dataset after which make a higher prediction of Iranian's EFL trainer's burn-out stage.

Table 1. MBI Dimensions

\begin{tabular}{|l|c|c|l|}
\hline & Low & Moderate & High \\
\hline Depersonalization (Cynicism) & $\leq 4$ & $5-12$ & $\geq 13$ \\
\hline Emotional Exhaustion & $\leq 16$ & $17-33$ & $\geq 34$ \\
\hline Sense of Personal Accomplishment & $\geq 39$ & $30-38$ & $\leq 29$ \\
\hline
\end{tabular}

\subsubsection{Experimental Design, Materials, and Methods}

Then, Statistical Package for Social Sciences (SPSS 18) turned into run to discover the burnout stage of every trainer. As it's far indicated in Table1, the lecturers have been divided into three groups: high-burned-out (HB), midburned-out (MB), and low-burned-out (LB). The amassed facts indicates that during all classes maximum of the lecturers are mid-burned-out. In non-public accomplishment and emotional exhaustion categoriez variety of highburned-out instructors are better than low-burned-out. But, in depersonalization class low-burned-out instructors are better than high-burned-out instructors. Part of this dataset is used to analyze the intercorrelations of coaching context, perceived occupational stress, and burnout with the mediating position of trainer resilience amongst Iranian EFL instructors (Karimi \& Adam, 2018).

Table 2. Depersonalization part in detail and number of chosen choices

\begin{tabular}{|l|l|l|l|l|l|l|l|}
\hline & Never & Very rarely & Rarely & Regularly & Often & Very Often & Always \\
\hline Q 5 & 144 & 264 & 360 & 472 & 192 & 0 & 0 \\
\hline Q 10 & 1112 & 152 & 64 & 104 & 0 & 0 & 0 \\
\hline Q 11 & 1168 & 176 & 40 & 40 & 8 & 0 & 0 \\
\hline Q 15 & 184 & 248 & 408 & 392 & 200 & 0 & 0 \\
\hline Q 22 & 560 & 416 & 224 & 112 & 72 & 48 & 0 \\
\hline
\end{tabular}

That includes 396 Low values, 989 Moderate values, and 47 High values. 


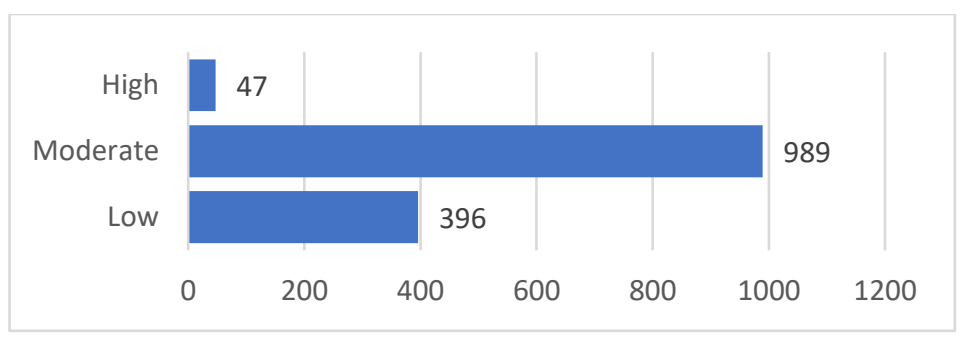

Figure 1. Depersonalization distribution

Table 3. Personal accomplishment part in detail and number of chosen choices

\begin{tabular}{|l|l|l|l|l|l|l|l|}
\hline & Never & Very rarely & Rarely & Regularly & Often & Very Often & Always \\
\hline Q 4 & 0 & 8 & 32 & 104 & 256 & 360 & 672 \\
\hline Q 7 & 0 & 488 & 288 & 296 & 152 & 64 & 144 \\
\hline Q 9 & 0 & 384 & 272 & 456 & 168 & 40 & 112 \\
\hline Q 12 & 0 & 16 & 24 & 128 & 240 & 424 & 600 \\
\hline Q 17 & 0 & 288 & 232 & 400 & 208 & 120 & 184 \\
\hline Q 18 & 0 & 32 & 32 & 104 & 272 & 328 & 664 \\
\hline Q 19 & 0 & 16 & 24 & 128 & 240 & 424 & 600 \\
\hline Q 21 & 0 & 288 & 232 & 400 & 208 & 120 & 184 \\
\hline
\end{tabular}

That includes 199 Low values, 590 Moderate values, and 590 High values.

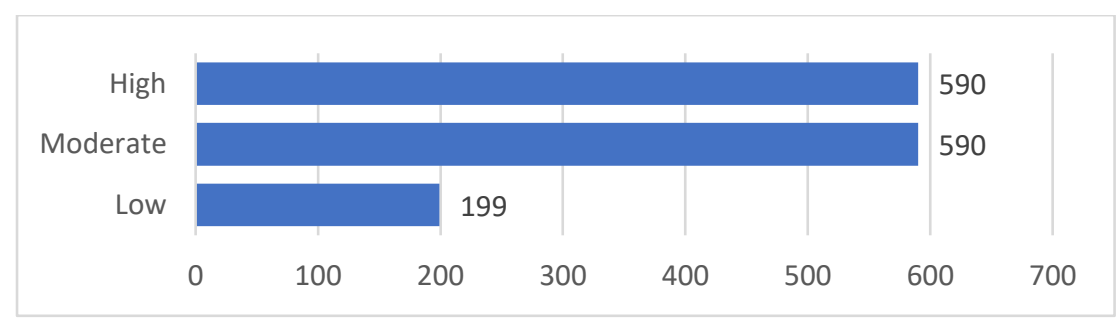

Figure 2. Personal accomplishment distribution

Table 4. Emotional exhaustion part in detail and number of chosen choices

\begin{tabular}{|l|l|l|l|l|l|l|l|}
\hline & Never & Very rarely & Rarely & Regularly & Often & Very Often & Always \\
\hline Q 1 & 0 & 352 & 160 & 464 & 208 & 168 & 80 \\
\hline
\end{tabular}




\begin{tabular}{|l|l|l|l|l|l|l|l|}
\hline Q 2 & 0 & 168 & 216 & 440 & 224 & 208 & 176 \\
\hline Q 3 & 0 & 272 & 328 & 376 & 272 & 104 & 80 \\
\hline Q 6 & 0 & 416 & 280 & 472 & 176 & 40 & 48 \\
\hline Q 8 & 0 & 320 & 240 & 416 & 224 & 112 & 120 \\
\hline Q 13 & 0 & 312 & 280 & 416 & 192 & 168 & 64 \\
\hline Q 14 & 0 & 112 & 120 & 152 & 264 & 256 & 528 \\
\hline Q 16 & 0 & 408 & 328 & 328 & 216 & 72 & 80 \\
\hline Q 20 & 0 & 536 & 248 & 360 & 168 & 48 & 72 \\
\hline
\end{tabular}

That includes 173 Low values, 910 Moderate values, and 349 High values.

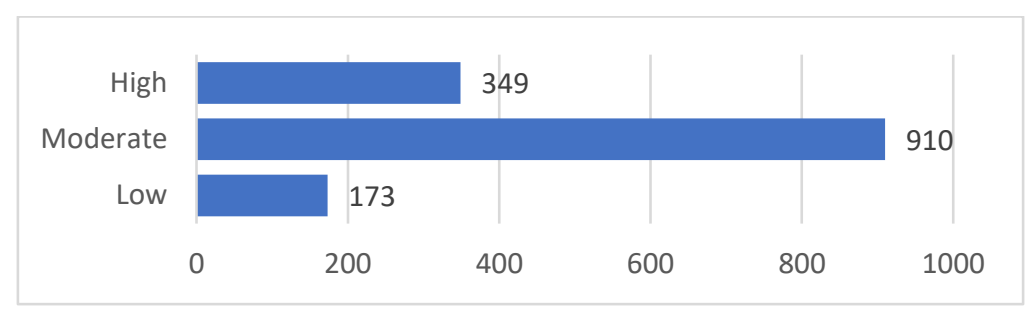

Figure 3. Emotional exhaustion distribution

Here is how to answer the question. The questions are from the Maslach Burnout Inventory and questionnaire:

1. I feel emotionally drained from my work.

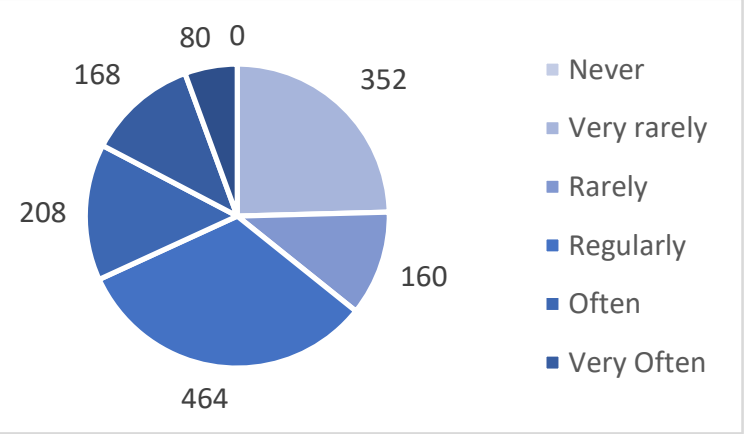

2. I feel used up at the end of the workday. 


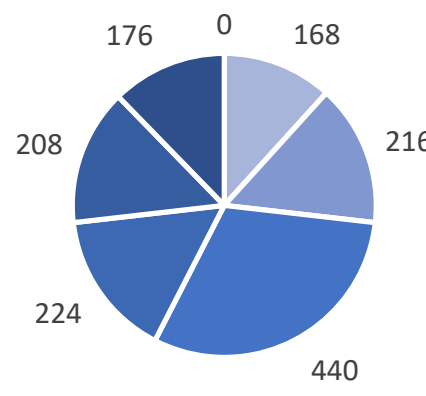

$$
\begin{aligned}
& \text { - Never } \\
& \text { - Very rarely } \\
& \text { - Rarely } \\
& \text { - Regularly } \\
& \text { - Often } \\
& \text { - Very Often }
\end{aligned}
$$

3. I feel fatigued when I get up in the morning and have to face another day on the job.

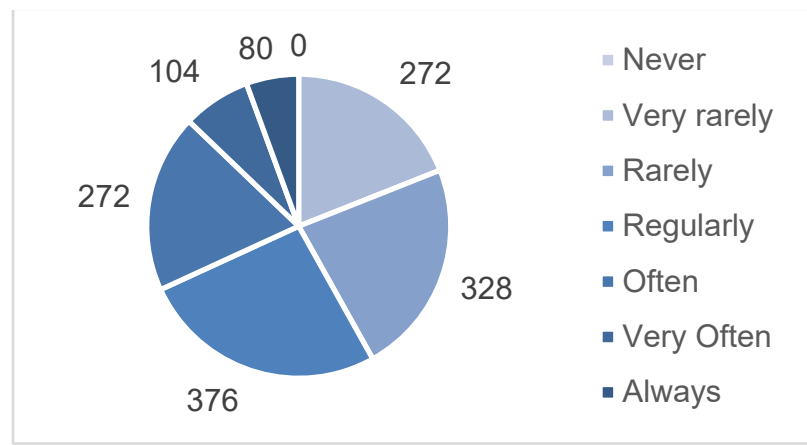

4. I can easily understand how my students feel about things

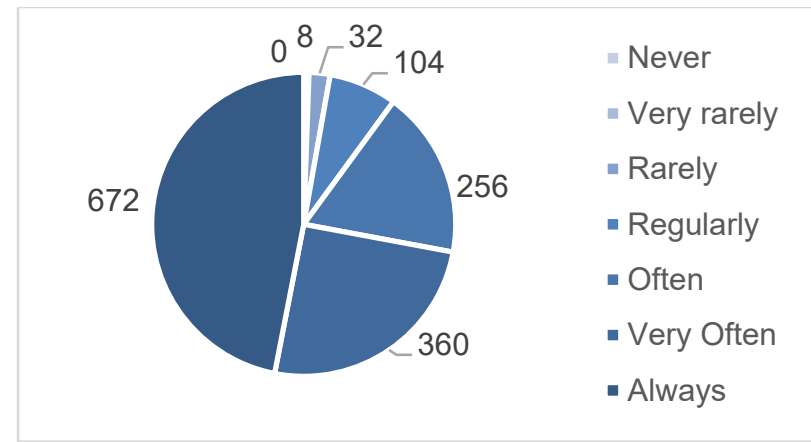

5. I feel I treat some students as if they were impersonal objects.

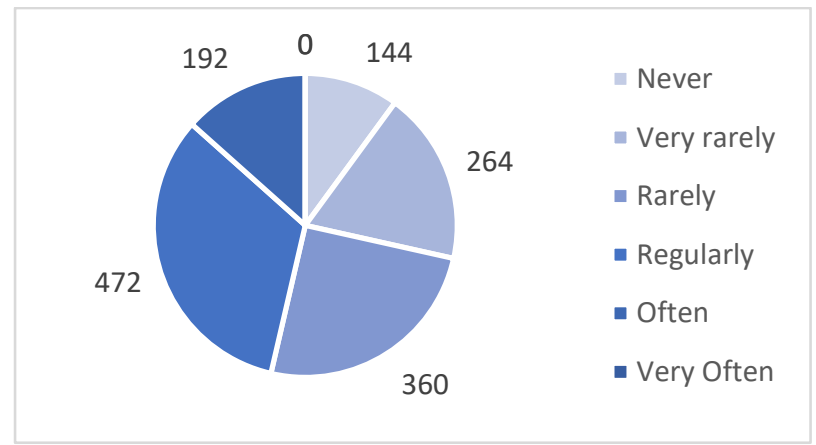

6. Working with people all day is really a strain for me. 


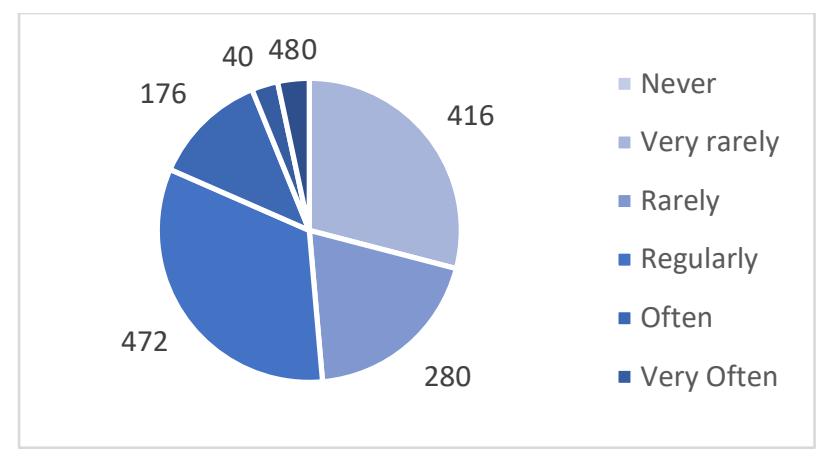

7. I deal very effectively with the problems of my students.

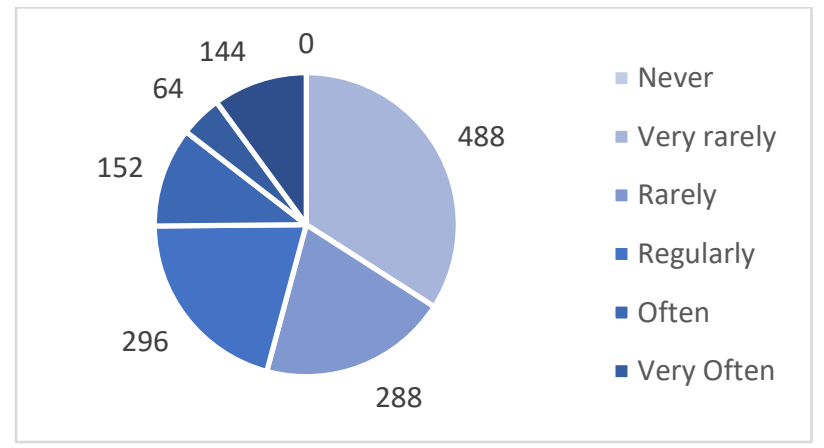

8. I feel burned out from my work.

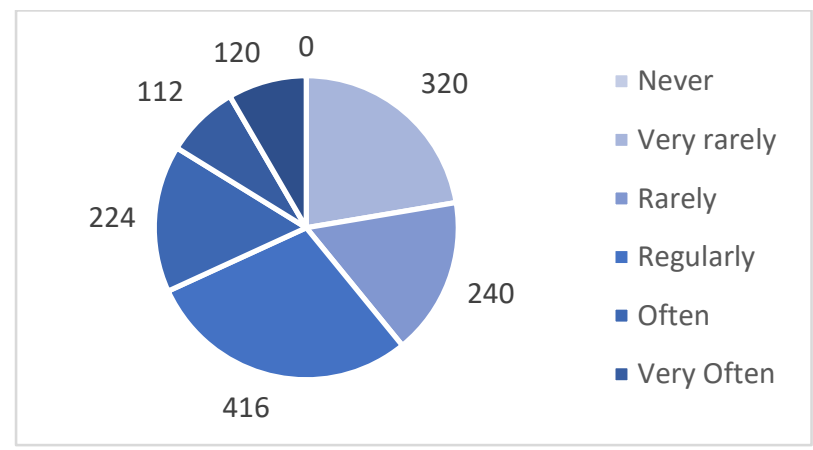

9. I feel that I am positively influencing other people's lives through my work.

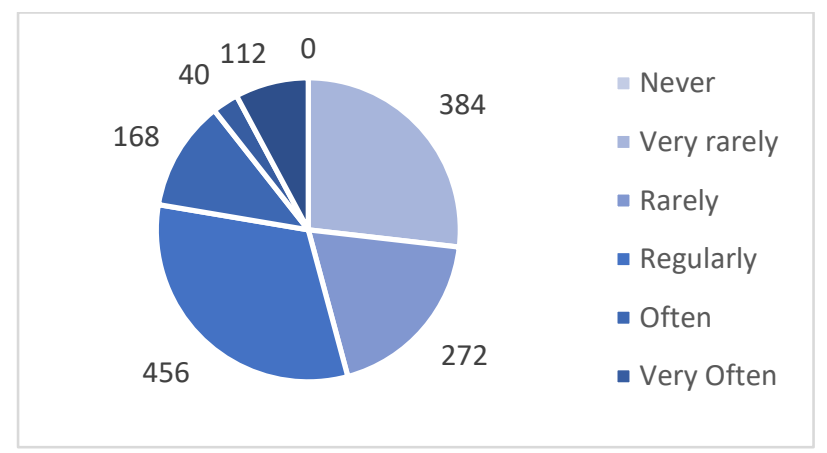


10. I 've become more callous toward people since I took this job.

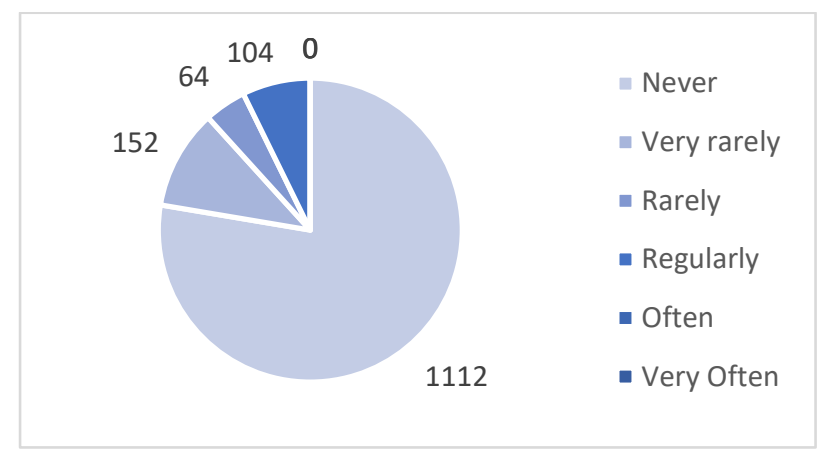

11. I worry that this job is hardening me emotionally.

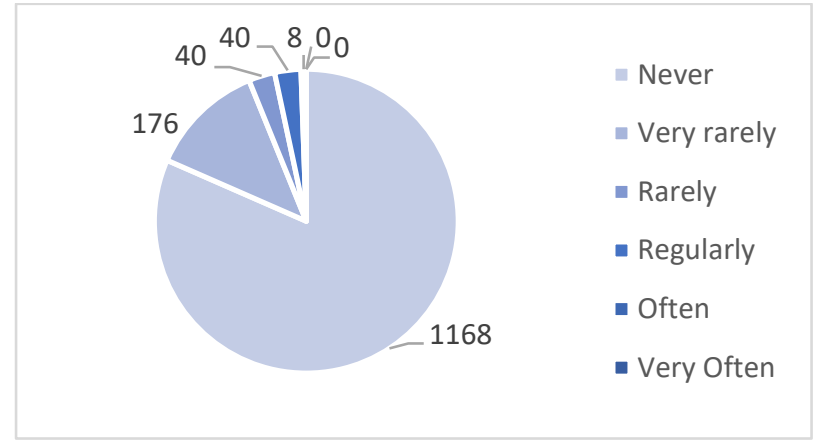

12. I feel very energetic.

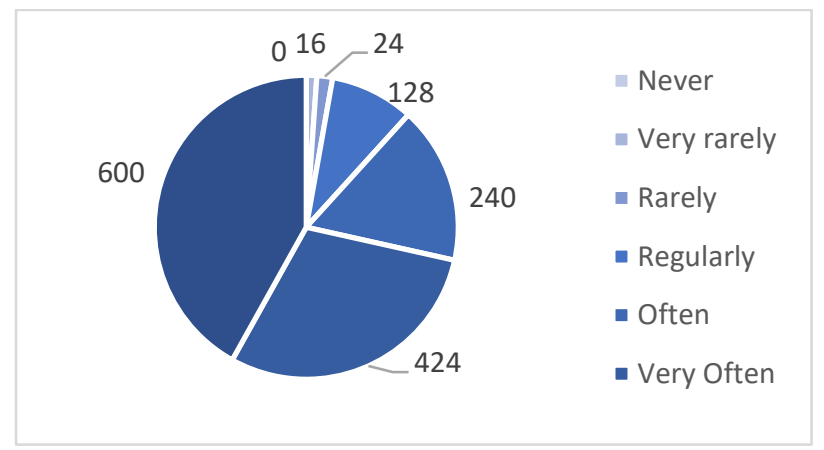

13. I feel frustrated by my job.

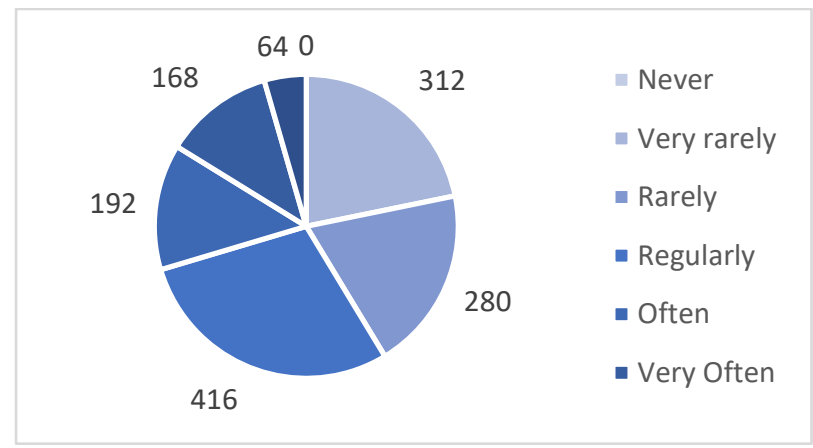

14. I feel I'm working too hard on my job. 


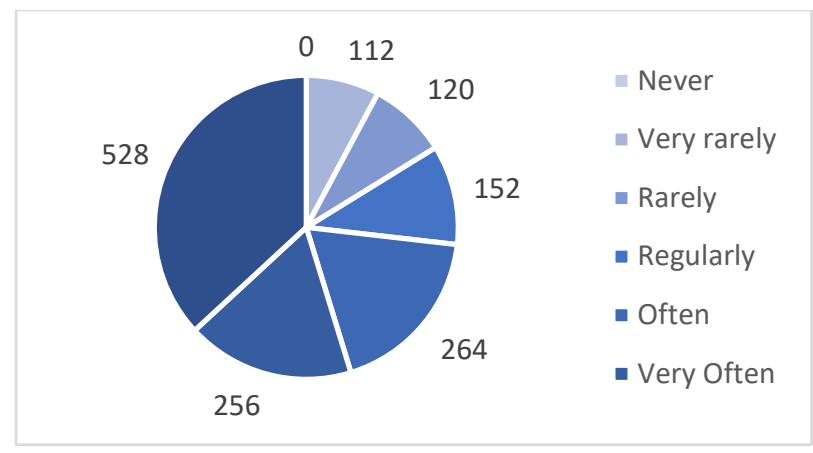

15. I don't really care what happens to some students.

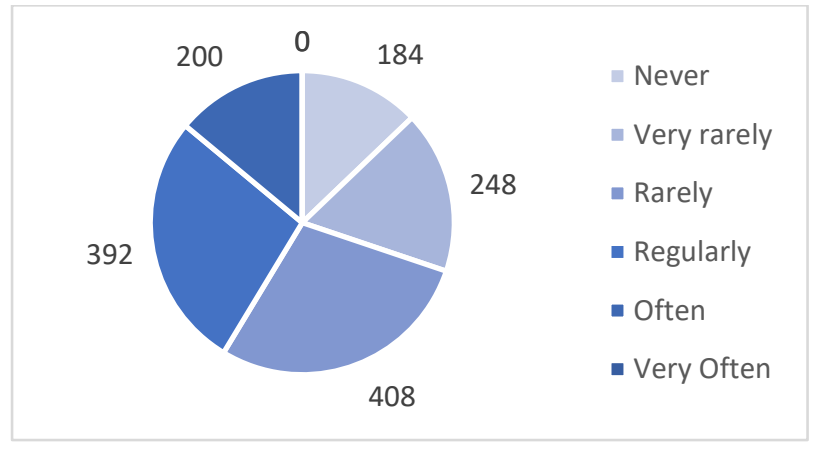

16. Working with people directly puts too much stress on me.

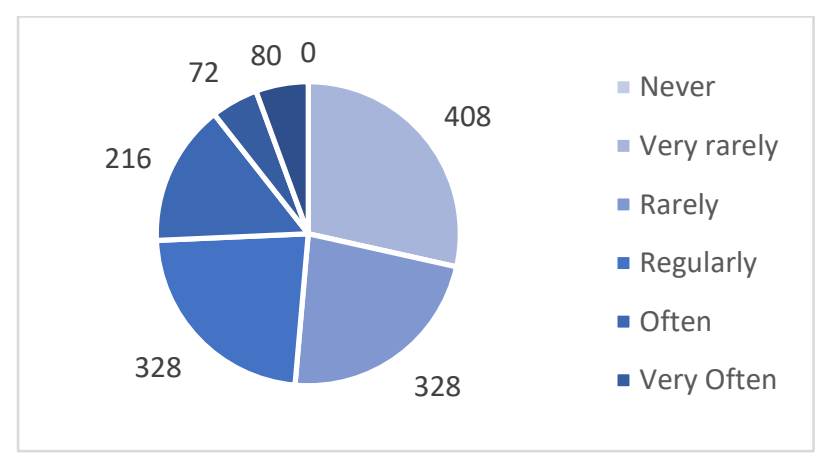

17. I can easily create a relaxed atmosphere with my students.

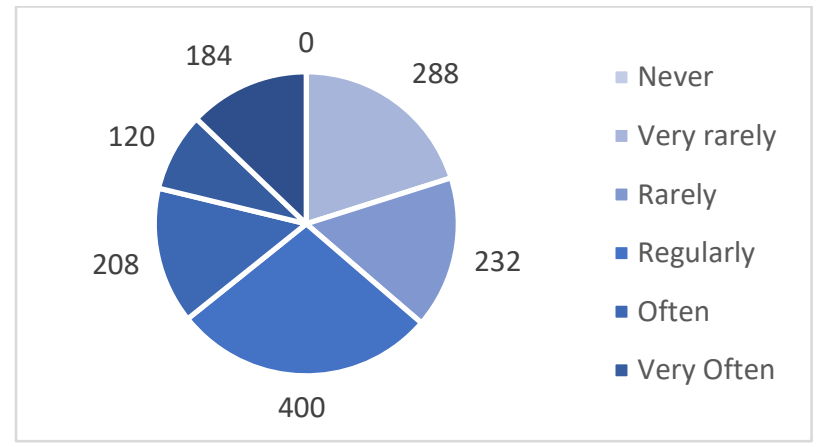


18. I feel exhilarated after working closely with my students.

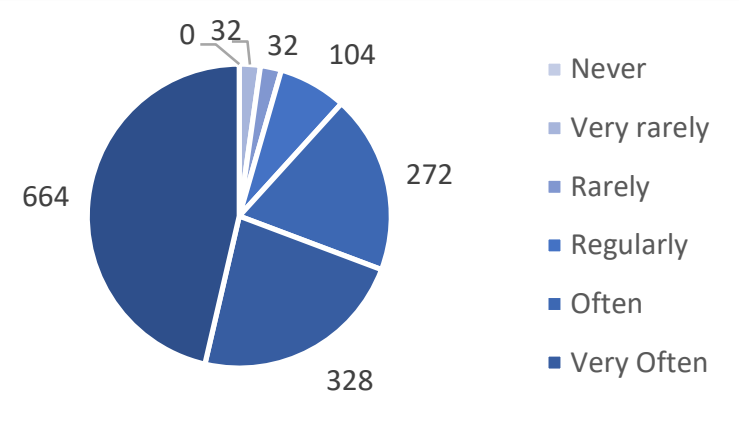

19. I have accomplished may worthwhile things in this job.

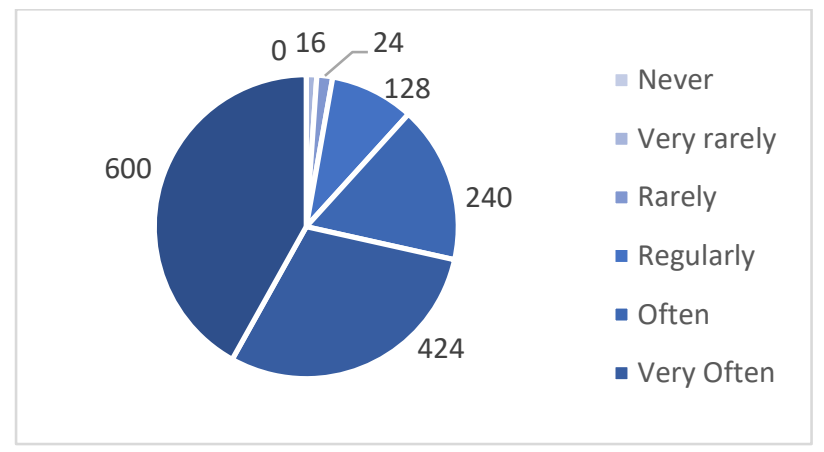

20. I feel like I'm at the end of my rope.

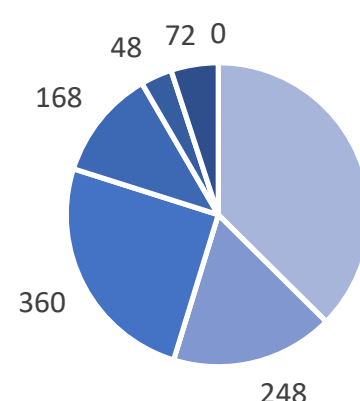

- Never

536

- Very rarely

- Rarely

- Regularly

- Often

- Very Often

21. In my work, I deal with emotional problems very calmly.

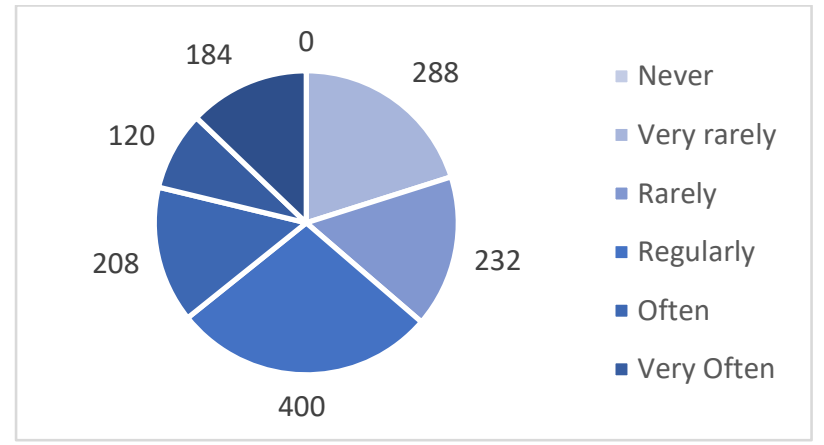


22. I feel students blame me for some of their problems.

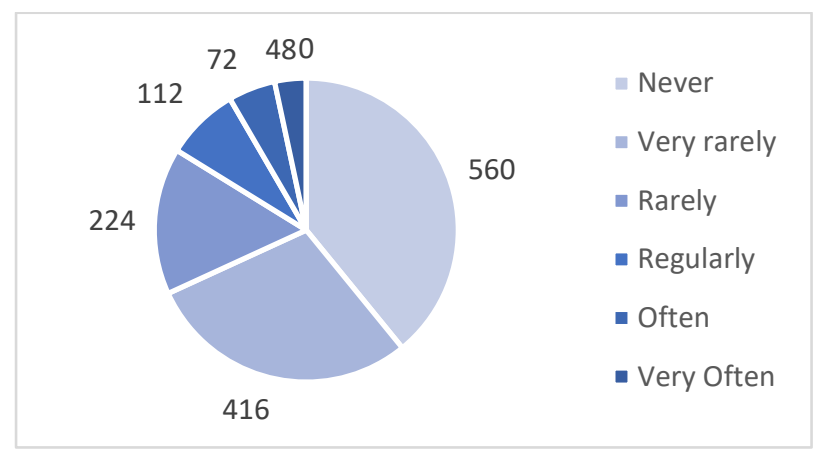

\subsection{Proposed approaches}

In this study, we used gadget gaining knowledge of (ML) to perceive the teacher's burnout level. The proposed version consists of dataset collection, preprocessing, characteristic extraction, and making use of gadget gaining knowledge of algorithm (Decision Tree, Support vector gadget, Support Vector Classifier, Support Vector Regression, Multi-Layer Perceptron, K- Nearest Neighbor, Gaussian Naïve Bayes, Random Forest, Quadratic Discriminant Analysis, Linear Discriminant Analysis) with the aid of using enforcing python programming language and evaluating it to 3 overall performance parameters as proven in Figure 4.

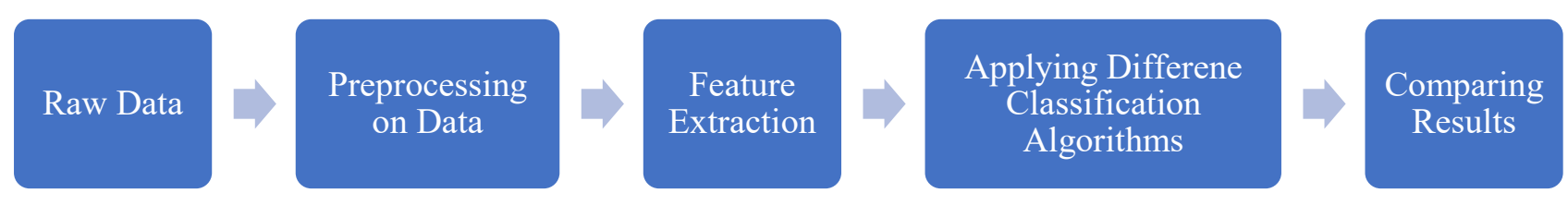

Figure 4. Overview of the used methodology

In this study, we used gadget gaining knowledge of (ML) to become aware of the teacher's burnout degree. The proposed version consists of dataset collection, preprocessing, function extraction, and making use of gadget gaining knowledge of algorithm (Decision Tree, Support vector gadget, Support Vector Classifier, Support Vector Regression, Multi-Layer Perceptron, K- Nearest Neighbor, Gaussian Naïve Bayes, Random Forest, Quadratic Discriminant Analysis, Linear Discriminant Analysis) through imposing python programming language and evaluating it to 3 overall performance parameters as proven in Figure 4.

We have used K-fold cross-validation (cv) to boom the dimensions of the dataset and enhance the performance of our version subsequently. K-fold cross-validation is a way for generalizing the records conduct and growing the k-fold instances of the records primarily based totally in this analysis. The manner includes dividing the dataset into k-folds after which generalizing the conduct and growing the records inputs, thereby growing the performance of our version. In our case, we carried out 10 -fold cross-validation due to the small dataset.

Classification Algorithm is a completely unique approach in records mining, in which you decompose given records and take each unmarried case from it. It classifies the instance right into a sure magnificence with a completely low opportunity of error. It is used to eliminate fashions that represent vital records lessons in the given records index. We have used a few class algorithms right here to become aware of the strain degree of individuals. We first skilled our records after which examined our version at the closing records. We have 3 extraordinary obligations as predicting emotional exhaustion, depersonalization, and Personal accomplishment on teachers. And in every aspect, we examine and are expecting the extent of burnout in 3 extraordinary ranges low, moderate, and excessive burnout. Our class assignment is used (0) as excessive, (1) as moderate, and (2) as low degree of burnout. Our used gadget gaining knowledge of algorithms are: 


\subsubsection{Decision Tree:}

DT is a non-parametric supervised getting to know method this is the usage of for category and regression. The intention of this category algorithms is to make a version that predicts the really well worth of a goal variable with the aid of using getting to know easy selection policies inferred from the records features.

\subsubsection{Support Vector Machine:}

This classifier normally works upon the hyper plan. This set of rules works upon the first-rate hyperplane that is greater beneficial in sorting new illustrations. In a 2-Dimensional aircraft, it's miles a line setting apart a aircraft in sections wherein every elegance lies on both of the sides.

\subsubsection{Linear Support Vector Classifier:}

SVC is useable to in shape at the furnished data, returning a "first-rate in shape" version that divides or categorizes the data. From there, as soon as acquiring the version, it'll then feed a few alternatives on your classifier to test what the "predicted" magnificence is. This makes this precise algorithmic rule as a substitute suitable for our uses, though you could use this for numerous situations.

\subsubsection{Support Vector Regression:}

SVR is a Support vector gadget and it helps each linear and non-linear regression issues and algorithms. The undertaking is to fit numerous times as possible among the traces while proscribing the margin violations.

\subsubsection{Multi-Layer Perceptron:}

An MLP is one of the synthetic neural community algorithms. Associate diploma MLP is considered as a logistical regression classifier anywhere the center is 1 st made over using a found out non-linear transformation. This transformation involves the enter records into the residence wherein it turns into linearly separable. This intermediate layer is said as a hidden layer. one hidden layer is ok to create MLPs as a general approximator. However, we're going to see sooner or later that there are giant blessings to exploiting numerous such hidden layers, i.e., the basis of deep learning.

\subsubsection{K- Nearest Neighbor:}

This set of rules works upon whether or not or now no longer the ok-NN nearest, the classifier is hired for association or relapse. it is a class club type inside which both a pupil belongs to A or B there may be no between. If there are three groups then the statistics is split into 3 corporations only. There is likewise a few compromises with the aid of using the neighbors, with the query being allocated to the magnificence, which one is its ok Nearest neighbors (ok may be a nice variety and a bit number). If $\mathrm{k}=1$, then the protest can be assigned to the magnificence of that solitary Nearest neighbor.

\subsubsection{Gaussian Naïve Bayes:}

A Gaussian Naive mathematician system might be a unique fashion of NB algorithm. It's especially used as soon as the alternatives have non-stop values. It's conjointly assumed that every one of the capabilities are following a Gaussian distribution i.e., conventional distribution. in the time period of gadget studying, naive Bayes classifiers incorporate a bunch of easy "probabilistic classifiers". They paintings upon the probability, extraordinarily scalable. They want several parameters which are directly withinside the variety of things (highlights/indicators) withinside the studying issue.

\subsubsection{Random Forest:}

This algorithmic software considers various name bushes, consequently forming a forest. it is also called an ensemble of choice tree algorithms. this can be used for class furthermore as regression. This set of rules attempts to 
are looking for out the most effective function indiscriminately amongst all of the features. In our experiment, we have got were given used one hundred choice bushes and Gini for the impurity index.

\subsubsection{Linear Discriminant Analysis:}

Linear discriminant Analysis (LDA), conventional discriminant evaluation (NDA), or discriminant function evaluation can be a generalization of Fisher' linear discriminant, a way hired in statistics, sample recognition, and opportunity fields, to hunt down a linear mixture of alternatives that characterizes or separates 2 or extra classes of items or events. The resulting mixture may also be used as a linear classifier, or, extra commonly, for spatial assets discount earlier than later classification.

\subsubsection{Quadratic Discriminant analysis:}

QDA is associated with LDA, anywhere it is meant that the sports from every class are generally distributed. now no longer like LDA, in QDA there may be no supposition that the variance of every of the kinds is identical. as soon as the normality assumption is true, the only ability test for the speculation that a given size is from a given magnificence is that the chance quantitative relation test.

\section{Results and discussions}

In this study, we've carried out 9 gadget gaining knowledge of algorithms (Decision Tree, Support vector gadget, Support Vector Classifier, Support Vector Regression, Multi-Layer Perceptron, K- Nearest Neighbor, Gaussian Naïve Bayes, Random Forest, Quadratic Discriminant Analysis, Linear Discriminant Analysis) and calculated the accuracy of these kinds of in 3 distinct elements of teachers' burn out (predicting emotional exhaustion, depersonalization and Personal accomplish). The effects are proven in Table 2.

Table 5. The result of predicting and classifying methods on the collected dataset

\begin{tabular}{|l|c|c|c|c|c|c|c|c|c|}
\hline & DT & SVC & SVR & MLP & KNN & GaussianNB & RF & QDA & LDA \\
\hline Depersonalization & 91 & 97 & 58 & 97 & 97 & 93 & 97 & 100 & 97 \\
\hline Emotional Exhaustion & 86 & 93 & 63 & 73 & 88 & 91 & 86 & 82 & 93 \\
\hline $\begin{array}{l}\text { Sense of Personal } \\
\text { Accomplishment }\end{array}$ & 91 & 98 & 59 & 98 & 98 & 94 & 98 & 100 & 98 \\
\hline
\end{tabular}

It is proven that each quadratic discriminant strategies have higher overall performance withinside the assignment of predicting teacher's burn out in phrases of emotional exhaustion, aid vector classifier and linear discriminant evaluation have the first-rate accuracy with $93 \%$ accurate prediction and withinside the depersonalization and private accomplish factors the quadratic discriminant evaluation has the first-rate accuracy with $100 \%$ accurate predictions. But, Linear 
Discriminant Analysis, Support Vector Classifier and, K- Nearest Neighbor strategies have excessive accuracy with greater than $97 \%$ accurate precisions (Figure 5).

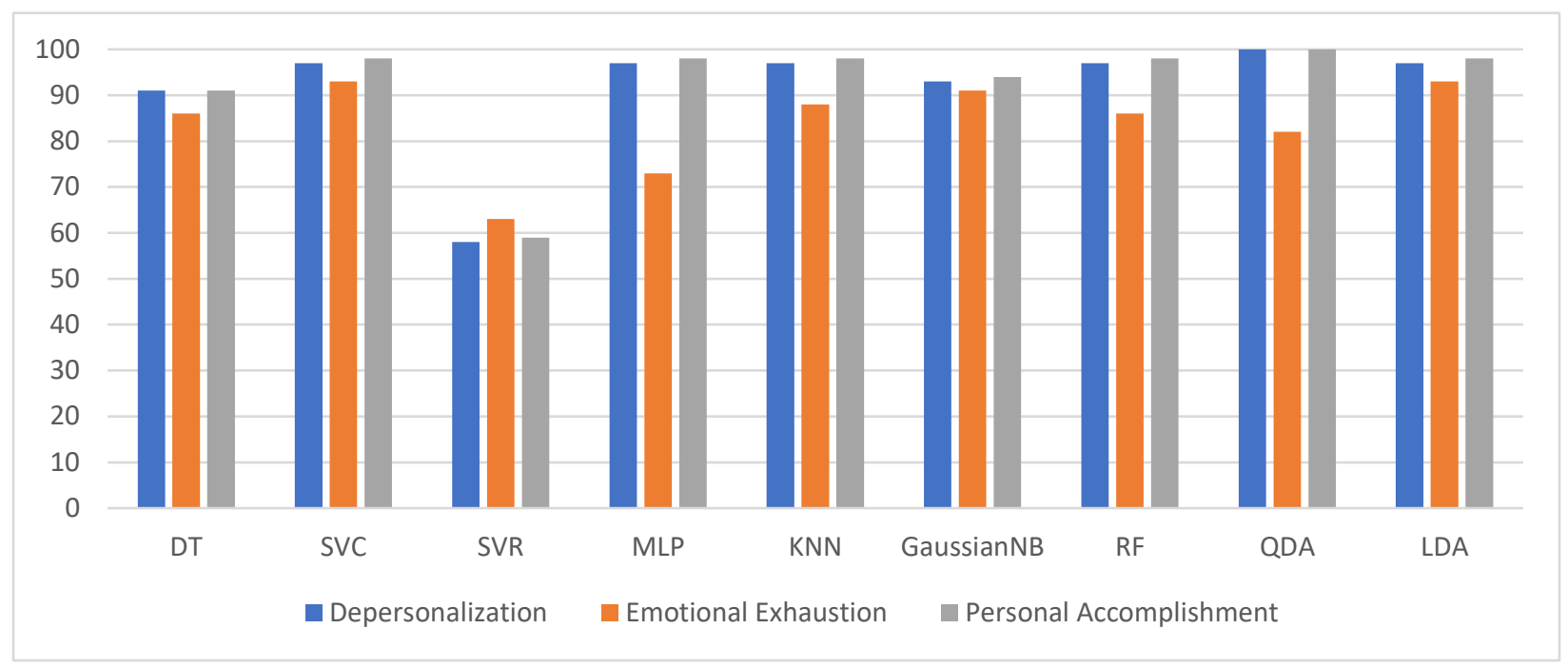

Figure 5. The chart of the classifier methods on the collected dataset

\section{Conclusion and Future Work}

We proposed a brand-new approach the usage of 9 system studying type algorithms (Decision Tree, Support vector system, Support Vector Classifier, Support Vector Regression, Multi-Layer Perceptron, K- Nearest Neighbor, Gaussian Naïve Bayes, Random Forest, Quadratic Discriminant Analysis, Linear Discriminant Analysis) on a dataset of 1433 EFL instructors to expect their burn out level. The effects are primarily based totally on 3 special categories: low, moderate, and high. Due to our small dataset, 10 -fold cross-validation become carried out to growth the quantity of statistics in our accrued dataset. Teachers' feeling of tiredness affects college students' conduct and effects which might also additionally bring about much less involvement of college students withinside the study room and reduce their fulfillment rate, as well. Therefore, the findings of this look at might also additionally have implications for the development of instructors' situations which, consequently, improves their pedagogical decision-making in special areas.

\section{Data availability statement}

Data is only accessible upon request and acceptance by the Institution where the data was obtained due to ethical constraints.

\section{References}

Abel, M. H., \& Sewell, J. (1999). Stress and burnout in rural and urban secondary school teachers. Journal of Educational Research, 92(5): 23-35.

Adams, E. (1999). Vocational teacher stress and internal characteristics. Journal of Vocational and Technical Education, 16(1): 28-36.

Ahuja, R., \& Banga, A. (2019). Mental stress detection in university students using machine learning algorithms. Procedia Computer Science, 152, 349-353. 
Aloe, A. M., Shisler, S. M., Norris, B. D., Nickerson, A. B., \& Rinker, T. W. (2014). A multivariate meta-analysis of student misbehavior and teacher burnout. Educational Research Review, 12: 30-44.

Bauernhofer, K., Bassa, D., Canazei, M., Jiménez, P., Paechter, M., Papousek, I., ... \& Weiss, E. M. (2018). Subtypes in clinical burnout patients enrolled in an employee rehabilitation program: differences in burnout profiles, depression, and recovery/resources-stress balance. BMC psychiatry, 18(1), 1-13.

Bianchi, R., Schonfeld, I. S., \& Laurent, E. (2014). Is burnout a depressive disorder? A reexamination with special focus on atypical depression. International Journal of Stress Management, 21(4), 307.

Bivona, K. N. (2002). Teacher morale: The impact of teaching experience, workplace conditions, and workload. (ERIC Document Reproduction Service No. ED467760).

Borg, M. G., \& Riding, R. J. (1991). Occupational stress and satisfaction in teaching. British educational research journal, 17(3), 263-281.

Bryne, J. J. (1998). Teacher as hunger artist: Burnout: its causes, effects, and remedies. Contemporary Education, 69(2): 86-91.

Cooper, C. L., \& Marshall, J. (1977). The Changing Pattern of British Executives' Wives: Its Effect on the Manager, His Wife and the Organisation. Management International Review, 37-46.

Corbin, C. M., Alamos, P., Lowenstein, A. E., Downer, J. T., Brown, J. L. (2019). The role of teacher-student relationships in predicting teachers' personal accomplishment and emotional exhaustion. Journal of School Psychology, 77: 1-12.

Dedrick, C. V., \& Raschke, D. B. (1990). The Special Educator and Job Stress. National Education Association Professional Library.

DelPozo-Banos, M., John, A., Petkov, N., Berridge, D. M., Southern, K., LLoyd, K., ... \& Travieso, C. M. (2018). Using neural networks with routine health records to identify suicide risk: feasibility study. JMIR mental health, 5(2), e10144.

Donald, J. G. (2000). Indicators of success: From concepts to classrooms. Paper presented at the annual conference of the American Educational Research Association, New Orleans.

Farber, B. A. (1991). Crisis in education: Stress and burnout in the American teacher. Jossey-Bass.

Flach, P. (2012). Machine learning: the art and science of algorithms that make sense of data. Cambridge University Press.

Gedam, S., \& Paul, S. (2020, July). Automatic Stress Detection Using Wearable Sensors and Machine Learning: A Review. In 2020 11th International Conference on Computing, Communication and Networking Technologies (ICCCNT) (pp. 1-7). IEEE.

Gelman, R. B. (2008). Demographic and occupational correlates of stress and burnout among urban school teachers (Doctoral dissertation, Hofstra University).

Gold, Y., \& Roth, R. A. (1993). Teachers managing stress and preventing burnout: The professional health development. London: Burgess Science Press.

Grządzielewska, M. (2021). Using Machine Learning in Burnout Prediction: A Survey. Child and Adolescent Social Work Journal, 1-6.

Hansen, J. I., \& Sullivan, B. A. (2003). Assessment of Workplace Stress: Occupational Stress, Its Consequences, and Common Causes of Teacher Stress. 
Karimi, M. N., \& Adam, S. B. (2018). A structural equation modelling analysis of the relationships between perceived occupational stress, burnout, and teacher resilience. Journal of Second Language Teacher Education, 1(1), 49-72.

Kessler, R. C., Warner, C. H., Ivany, C., Petukhova, M. V., Rose, S., Bromet, E. J., ... \& Ursano, R. J. (2015). Predicting suicides after psychiatric hospitalization in US Army soldiers: the Army Study to Assess Risk and Resilience in Servicemembers (Army STARRS). JAMA psychiatry, 72(1), 49-57.

Kurbatov, V., Shaughnessy, M., Baratta, V., Heller, D. R., Freedman-Weiss, M., Resio, B. J., ... \& Yoo, P. S. (2020). Application of advanced bioinformatics to understand and predict burnout among surgical trainees. Journal of surgical education, 77(3), 499-507.

Kyriacou, C. (2001). Teacher stress: Directions for future research. Educational Review, 53(1): 27-35.

Lee, Y. L., Chou, W., Chien, T. W., Chou, P. H., Yeh, Y. T., \& Lee, H. F. (2020). An app developed for detecting nurse burnouts using the convolutional neural networks in Microsoft Excel: population-based questionnaire study. JMIR medical informatics, 8(5), e16528.

Leiter, M. P., \& Robichaud, L. (1997). Relationships of occupational hazards with burnout: An assessment of measures and models. Journal of Occupational Health Psychology, 2(1), 35.

Lu, P., Zhang, W., Ma, L., \& Zhao, Q. (2020, July). A Framework of Real-Time Stress Monitoring and Intervention System. In International Conference on Human-Computer Interaction (pp. 166-175). Springer, Cham.

Male, D. B., \& May, D. (1997). Research Section: Stress, Burnout and Workload in Teachers of Children with Special Educational Needs. British Journal of Special Education, 24(3): 133-140.

Maslach, C., \& Leiter, M. P. (1999). Teacher burnout: A research agenda. In R. Vandenberghe \& A. M. Huberman (Eds.), Understanding and preventing teacher burnout: A sourcebook of international research and practice (pp. 295-303). Cambridge: Cambridge University Press.

Maslach, C., Jackson, S. E., \& Leiter, M. P. (1997). Maslach Burnout Inventory. In C. P. Zalaquett \& R. J. Wood (Eds.), Evaluating stress: A book of resources (pp. 191-218). Lanhan, MD: The Scarecrow Press

Mitchell, T. M. (2017). Key ideas in machine learning. Mach. Learn, 1-11.

Okojie, M. C. (2011). The changing roles of teachers in a technology learning setting. International Journal of Instructional Media, 38(1): 17-26.

Parkay, F., Greenwood, G., Olenjik, S., \& Proller, N. (1988). A Study of the relationships among teacher efficacy, locus of control, and stress. Journal of Research \& Development in Education, 21(4): 13-22

Pollard, A., \& Collins, J. (2005). Reflective teaching. Bloomsbury Publishing.

Rajendran, N., Watt, H. M. G., \& Richardson, P. W. (2020). Teacher burnout and turnover intent. The Australian Educational Researcher, 47: 477-500.

Schaufeli, W. B., Bakker, A. B., \& Van Rhenen, W. (2009). How changes in job demands and resources predict burnout, work engagement, and sickness absenteeism. Journal of Organizational Behavior, 30(7): 893-917.

Schonfeld, I. S., \& Bianchi, R. (2016). Burnout and depression: two entities or one?. Journal of clinical psychology, 72(1), 22-37.

Silva, E., Aguiar, J., Reis, L. P., e Sá, J. O., Gonçalves, J., \& Carvalho, V. (2020). Stress among Portuguese medical students: the eustress solution. Journal of medical systems, 44(2), 1-6.

Tan, P. N., Steinbach, M., \& Kumar, V. (2016). Introduction to data mining. Pearson Education India. 
Taylor, S., Jaques, N., Nosakhare, E., Sano, A., \& Picard, R. (2017). Personalized multitask learning for predicting tomorrow's mood, stress, and health. IEEE Transactions on Affective Computing, 11(2), 200-213.

Travers, C. J., \& Cooper, C. L. (1996). Teachers under pressure: Stress in the teaching profession, London, UK: Routledge.

Webb, C. A., Cohen, Z. D., Beard, C., Forgeard, M., Peckham, A. D., \& Björgvinsson, T. (2020). Personalized prognostic prediction of treatment outcome for depressed patients in a naturalistic psychiatric hospital setting: A comparison of machine learning approaches. Journal of consulting and clinical psychology, 88(1), 25.

Wisniewski, L., \& Gargiulo, R. M. (1997). Occupational stress and burnout among special educators: A review of the literature. The Journal of Special Education, 31(3): 325-346.

Zhernova, P., Bodyanskiy, Y., Yatsenko, B., \& Zavgorodnii, I. (2020, February). Detection and prevention of professional burnout using machine learning methods. In 2020 IEEE 15th International Conference on Advanced Trends in Radioelectronics, Telecommunications and Computer Engineering (TCSET) (pp. 218-221). IEEE. 


\section{Declarations}

\section{Funding}

This paper provided without using fund from any organization.

Conflicts of interest/Competing interests (include appropriate disclosures)

We wish to restrict or otherwise manage adverse research findings and show the importance od computer techniques in the education quality and teacher's health.

\section{Availability of data and material}

The data is available with the request from the corresponding email address.

\section{Code availability}

The code is available with the request from the corresponding email address.

Ethics approval (include appropriate approvals or waivers)

All the collected data was based on the Maslach Burnout Inventory and all participants were aware about it.

Consent to participate (include appropriate statements)

All the participants were older than 18 and were worked as teacher at institutes and schools.

Consent for publication (include appropriate statements)

In the collected and used data the participants personal details are not needed and are not collected. 